Proc. of the International Conference on Mechanochemistry and Mechanical Alloying, Kraków, Poland, June 22-26, 2014

\title{
The Study of Magnetization in Strong Magnetic Fields for Alloys $\mathrm{Fe}_{60} \mathrm{Co}_{10} \mathrm{~W}_{x} \mathrm{Nb}_{2} \mathrm{Y}_{8} \mathrm{~B}_{20-x}(x=0,1)$
}

\author{
S. Garus, M. NabiaŁeK, K. BŁoch and J. Garus \\ Częstochowa University of Technology, Faculty of Production Engineering and Materials Technology, \\ Institute of Physics, al. Armii Krajowej 19, 42-200 Częstochowa, Poland
}

\begin{abstract}
The study analyzed the influence of structural defects on the process of magnetization in the area called the approach to ferromagnetic saturation for bulk $\mathrm{Fe}_{60} \mathrm{Co}_{10} \mathrm{~W}_{x} \mathrm{Nb}_{2} \mathrm{Y}_{8} \mathrm{~B}_{20-x}(x=0,1)$ alloys. For this purpose, the magnetization studies were performed in the fields range of $0 \mathrm{~T}$ to $2 \mathrm{~T}$ using a LakeShore vibrating magnetometer. On the basis of the Kronmüller theory an analysis of the magnetization curves was conducted and the type of occurring structural defects in the studied alloys was established. Then, using a Monte Carlo method the effective anisotropy of the tested samples was designated.
\end{abstract}

DOI: 10.12693 /APhysPolA.126.957

PACS: 75.50.-y, 75.50.Kj, 75.30.Ds, 75.20.En, 75.47.Np, 75.50.Bb, 75.60.Ej

\section{Introduction}

Ferromagnetic bulk amorphous materials based on iron, cobalt and boron due to their unique soft magnetic properties are interesting because of their application in the power industry, but also because of the processes occurring inside the sample during the magnetization process $[1-5]$.

Various additives to the main alloy allow to change the physical properties of the material and adapt them to specific application requirements. The nanocrystalline alloys from FINEMET and NANOPERM group are being made in the form of thin ribbons, which significantly restricts their applications [6-8]. In the electrotechnical industry the need for the bulk materials with good soft magnetic properties $\left(\mu_{0} M>1 \mathrm{~T}, H_{\mathrm{c}}<100 \mathrm{~A} / \mathrm{m}\right)$ exists. These materials could be used for example for magnetic cores with different shapes. The FeCoB-based bulk amorphous alloys are an example of these materials [9-12].

When using a very high cooling rate, metallic glasses with unique physical structural properties can be obtained. The most commonly used methods for the preparation of metallic glasses, allowing good quality of the resulting samples, are: the quenching of the molten alloy on a rotating copper cylinder (melt spinning), the injection and suction of the molten alloy into a cooled copper mould (injection and suction casting method). Methods of injection and suction casting may be used simultaneously to give an additional possibility to control the process.

The rapid decrease of the atoms kinetic energy during the metallic glasses production results in a metastable amorphous structure. Inside this structure, similarly as for crystalline materials, there may be defects such as free

corresponding author; e-mail: sg@wip.pcz.pl volume, which by analogy to the crystal lattice vacancies are called point defects. Point defect conglomerates are called quasidislocational dipoles.

\subsection{Theoretical model}

The Kronmüller's theory describes the influence of amorphous structure defects on the deviation from the saturation magnetization initial curve at high fields [13-17]; this can be described by the equation

$$
\begin{aligned}
& \mu_{0} M(H)=\mu_{0} M_{s} \\
& \quad \times\left(1-\sigma_{i \in 1 / 2,1,2} \frac{a_{i}}{\left(\mu_{0} H\right)^{1 / 2}}\right)+b\left(\mu_{0} H\right)^{1 / 2},
\end{aligned}
$$

where $M_{s}$ - spontaneous magnetization, $\mu_{0}$ - permeability of free space, $H$ - the external magnetic field intensity, $a_{i}$ - the slope of the corresponding linear fits, $b\left(\mu_{0} M\right)$ - slope coefficient as a function of $\left(\mu_{0} H\right)^{1 / 2}$ (Holstein-Primakoff paraprocess).

Coefficients $a_{i}$ and $b$ from Eq. (1) can be described by

$$
\begin{aligned}
& \frac{a_{1 / 2}}{\left(\mu_{0} H\right)^{1 / 2}}=\mu_{0} \frac{3}{20 A_{\mathrm{ex}}}\left(\frac{1+r}{1-r} G \lambda_{s} \Delta V\right)^{2} \\
& \times N\left(\frac{2 A_{\mathrm{ex}}}{\mu_{0} M_{s}}\right)^{1 / 2} \frac{1}{\left(\mu_{0} H\right)^{1 / 2}}, \\
& \frac{a_{1}}{\left(\mu_{0} H\right)}=1.1 \mu_{0} \frac{G^{2} \lambda_{s}^{2}}{(1-\nu)^{2}} \frac{N b_{e f f}}{M_{s} A_{e x}} D_{d i p}^{2} \frac{1}{\mu_{0} H}, \\
& \frac{a_{2}}{\left(\mu_{0} H\right)^{2}}=0.456 \mu_{0} \frac{G^{2} \lambda_{s}^{2}}{(1-\nu)^{2}} \frac{N b_{\mathrm{eff}}}{M_{s}^{2}} D_{\mathrm{dip}}^{2} \frac{1}{\left(\mu_{0} H\right)^{2}}, \\
& b=3.54 g \mu_{0} \mu_{\mathrm{B}}\left(\frac{1}{4 \pi D_{s p f}}\right)^{3 / 2} k T\left(g \mu_{\mathrm{B}}\right)^{1 / 2},
\end{aligned}
$$

where $k$ - Boltzmann's constant, $\mu_{\mathrm{B}}$ - Bohr magneton, $g$ - gyromagnetic factor, $\Delta V$ - change in the volume due to the occurrence of a point defect characterized by a bulk density of $N, G$ - transverse elastic shear modulus, $A_{\text {ex }}$ - exchange constant, $\lambda_{s}$ - magnetostriction constant, $r$ - Poisson's ratio. 
Determination of coefficient $b$ allows the specification of parameters such as: exchange distance $l_{H}$, exchange constant $A_{\text {ex }}$ and spin-wave stiffness parameter $D_{\text {spf }}$ determined from Eq. (5) [18-20]:

$$
\begin{aligned}
& A_{\mathrm{ex}}=\frac{M_{s} D_{s p f}}{2 g \mu_{\mathrm{B}}}, \\
& l_{H}=\sqrt{\frac{2 A_{\mathrm{ex}}}{\mu_{0} H M_{s}}} .
\end{aligned}
$$

The value of the effective anisotropy is equal to the surface area above the initial magnetization curves restricted by the value of the saturation of magnetic polarization. One of the numerical methods for the establishing of the surface area with high precision is the Monte Carlo method. In this method random points within the limit of integration are drawn. The higher the number of the drawn points, the more accurate is the result. It is important to choose a good quality generator of quasirandom numbers - with even covering of the surface. Then, the number of points in the area within the limits of integration to the total number of the measurement points is calculated. The multiplication of the division product by the value of the field $\mu_{0} M_{s} \times H$ gives the value of the integral.

$$
K_{e f}=\mu_{0} M_{s} H-\int_{0}^{H} \mu_{0} M(H) d H
$$

The aim of the study was to investigate the structure defects influence on the magnetization process by using the approach to ferromagnetic saturation theory in $\mathrm{Fe}_{60} \mathrm{Co}_{10} \mathrm{~W}_{x} \mathrm{Nb}_{2} \mathrm{Y}_{8} \mathrm{~B}_{20-x}(x=0,1)$ bulk amorphous alloys. The effective anisotropy of the studied alloys was designated.

\section{Material and experimental results}

The sample was made by melting high purity components in a protective argon atmosphere. Obtained material, made by injection casting method, was in the form of plates with dimensions of $1 \times 10 \times 10 \mathrm{~mm}^{3}$. The structure was examined by using D8 ADVANCE Bruker Xray diffractometer. Studies of magnetic polarization as a function of the magnetic field to the $2 \mathrm{~T}$ was performed using LakeShore vibrating magnetometer.

Figure 1 shows the results of X-ray diffraction. The observed diffraction peaks with a large width are characteristic for amorphous structure materials.

Figure 2 shows measured initial magnetization curves. magnetic polarization of the sample without the tungsten addition was $1.14 \mathrm{~T}$, while the tungsten admixture instead of boron caused a decrease in the magnetic polarization to $1.07 \mathrm{~T}$.

High-field magnetic polarization curve as a function of $\left(\mu_{0} H\right)^{-1 / 2}$ showing the effect of point defects in the magnetization process is shown in Fig. 3a. Linear dependence was observed for the field $0.24 \div 1.1 \mathrm{~T}$. In Fig. $3 \mathrm{~b}$ high-field magnetic polarization curve as a function of $\left(\mu_{0} H\right)^{1 / 2}$ shows the effect of the external field to suppress

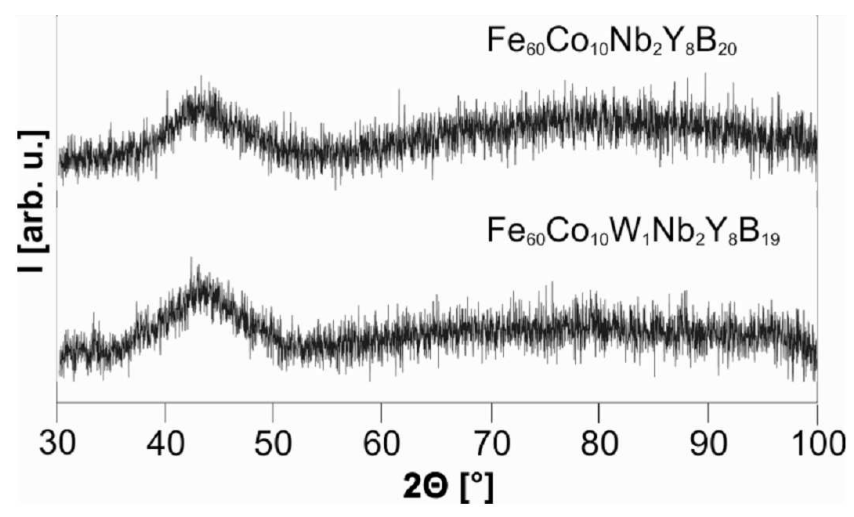

Fig. 1. X-ray diffraction patterns.

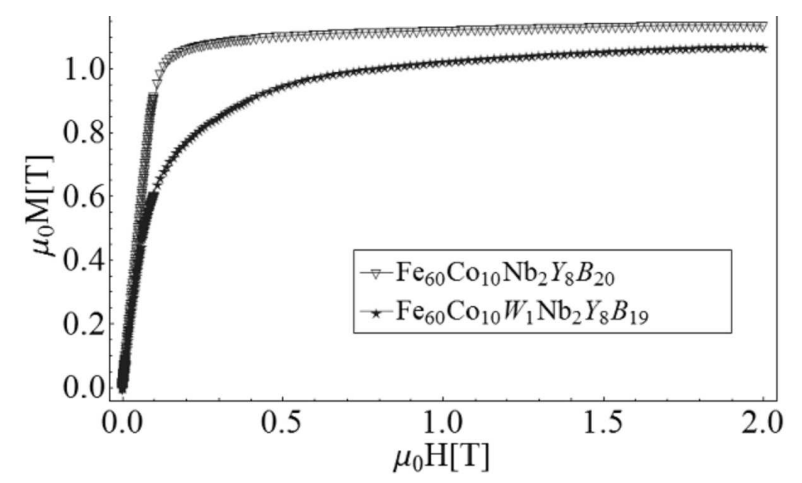

Fig. 2. High-field magnetic polarization curve as a function of $\left(\mu_{0} H\right)$.

thermally excited spin waves. The Holstein-Primakoff paraprocess transition was established under the condition of magnetic induction equal to $1.1 \mathrm{~T}$.

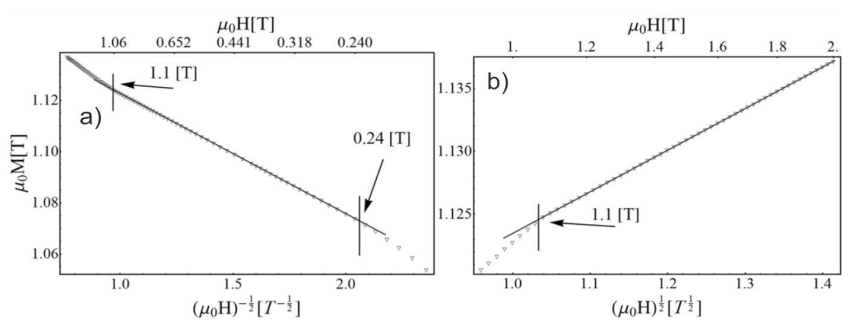

Fig. 3. High-field magnetic polarization curves as a function of $\left(\mu_{0} H\right)^{-1 / 2}$ and $\left(\mu_{0} H\right)^{1 / 2}$ for $\mathrm{Fe}_{60} \mathrm{Co}_{10} \mathrm{Nb}_{2} \mathrm{Y}_{8} \mathrm{~B}_{20}$ alloy.

Figure 4 shows the high-field magnetization curves for $\mathrm{Fe}_{60} \mathrm{Co}_{10} \mathrm{~W}_{1} \mathrm{Nb}_{2} \mathrm{Y}_{8} \mathrm{~B}_{19}$ alloy. A linear curve-fit was observed as a function of $\left(\mu_{0} H\right)^{-1 / 2}$ for the field from $0.047 \mathrm{~T}$ to $0.3 \mathrm{~T}$, where point defects affect the magnetization process and as a function of $\left(\mu_{0} H\right)^{-1}$ from $0.3 \mathrm{~T}$ to $1.2 \mathrm{~T}$ for linear conglomerates. For $\mathrm{Fe}_{60} \mathrm{Co}_{10} \mathrm{~W}_{1} \mathrm{Nb}_{2} \mathrm{Y}_{8} \mathrm{~B}_{19}$ alloy the transition field to paraprocess was $1.2 \mathrm{~T}$. The results obtained from the analysis of magnetization studies are summarized in Table, where $\sigma$ are the standard deviations. 


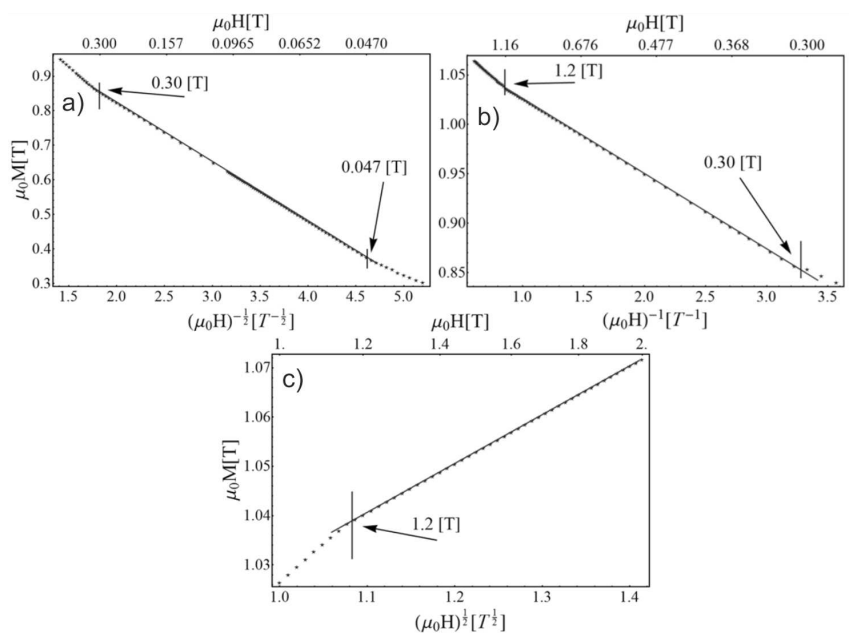

Fig. 4. High-field magnetization curves as function of $\left(\mu_{0} H\right)^{-1 / 2}, \quad\left(\mu_{0} H\right)^{-1}$ and $\left(\mu_{0} H\right)^{1 / 2}$ for $\mathrm{Fe}_{60} \mathrm{Co}_{10} \mathrm{~W}_{1} \mathrm{Nb}_{2} \mathrm{Y}_{8} \mathrm{~B}_{19}$ alloy.

TABLE I

The results obtained from the analysis of magnetization studies of $\mathrm{Fe}_{60} \mathrm{Co}_{10} \mathrm{~W}_{x} \mathrm{Nb}_{2} \mathrm{Y}_{8} \mathrm{~B}_{20-x}$ (where $x=0,1$ ) alloys.

\begin{tabular}{c|c|c}
\hline \hline & \multicolumn{2}{|c}{$\mathrm{Fe}_{60} \mathrm{Co}_{10} \mathrm{~W}_{x} \mathrm{Nb}_{2} \mathrm{Y}_{8} \mathrm{~B}_{20-x}$} \\
\cline { 2 - 3 } & $x=0$ & $x=1$ \\
\hline $\mathrm{M}_{s}[\mathrm{~T}]$ & 1.14 & 1.07 \\
$a_{1 / 2}\left[10^{-2} \mathrm{~T}^{-1 / 2}\right]$ & 4.70 & 17.16 \\
$\sigma\left(a_{1 / 2}\left[10^{-2} \mathrm{~T}^{-1 / 2}\right]\right.$ & 0.15 & 0.43 \\
$a_{1}\left[10^{-2} \mathrm{~T}^{-1}\right]$ & - & 7.61 \\
$\sigma\left(a_{1}\right)\left[10^{-2} \mathrm{~T}^{-1}\right]$ & - & 0.52 \\
$\mu_{0} H_{\mathrm{p}}[\mathrm{T}]$ & 1.06 & 1.18 \\
$b\left[\mathrm{~T}^{1 / 2}\right]$ & 3.31 & 9.91 \\
$\sigma(b)\left[10^{-} 2 \mathrm{~T}^{1 / 2}\right]$ & 0.15 & 0.11 \\
$D_{s p f}\left[\mathrm{meV} \mathrm{nm}{ }^{2}\right]$ & 64 & 31 \\
$l_{h}[\mathrm{~nm}]$ & 2.24 & 1.47 \\
$A_{\text {ex }}\left[10^{-12} \mathrm{~J} / \mathrm{m}\right]$ & 2.47 & 1.12 \\
$K_{\text {ef }}\left[\mathrm{kJ} / \mathrm{m}^{3}\right]$ & 85 & 178
\end{tabular}

\section{Conclusions}

The addition of one percent (by mass) of tungsten dopant, instead of boron, to the $\mathrm{Fe}_{60} \mathrm{Co}_{10} \mathrm{Nb}_{2} \mathrm{Y}_{8} \mathrm{~B}_{20}$ alloy reduced the saturation magnetization thereof. In the alloy without the tungsten addition major impact in the magnetization process at high fields had point defects, admixture of tungsten caused the formation of quasidislocational dipoles. The admixture of tungsten caused a decrease in the chemical short-range order because the values of the spin-wave stiffness parameter decreased. The values of the constant and distance exchange parameters also were decreased, and the value of effective anisotropy was increased.

\section{References}

[1] K. Sobczyk, J. Świerczek, J. Gondro, J. Zbroszczyk, W. Ciurzyńska, J. Olszewski, P. Brągiel, A. Łukiewska, J. Rzacki, M. Nabiałek, J. Magn. Magn. Mater. 324, 540 (2012).

[2] K. Błoch, Arch. Mater. Sci. Eng. 64, 97 (2013).

[3] K. Sobczyk, J. Zbroszczyk, M. Nabiałek, J. Olszewski, P. Bragiel, J. Swierczek, W. Ciurzyńska, A. Łukiewska, M. Lubas, M. Szota, Arch. Metall. Mater. 53, 855 (2008).

[4] K. Błoch, M. Nabiałek, P. Pietrusiewicz, J. Gondro, M. Dośpiał, M. Szota, K. Gruszka, Acta Phys. Pol. A 126, 108 (2014).

[5] M.G. Nabiałek, P. Pietrusiewicz, M.J. Dospiał, M. Szota, K. Błoch, K. Gruszka, K. Oźga, S. Garus, J. Alloys Comp. 615, S51 (2014).

[6] G. Pozo López, L.M. Fabietti, A.M. Condó, S.E. Urreta, J. Magn. Magn. Mater. 322, 3088 (2010).

[7] B. Hernando, P. Alvarez, J.D. Santos, P. Gorría, M.L. Sánchez, J. Olivera, M.J. Pérez, V.M. Prida, J. Magn. Magn. Mater. 300, e59\&\#8211; e62e60 (2006).

[8] J. Gondro, J. Świerczek, J. Rzącki, W. Ciurzyńska, J. Olszewski, J. Zbroszczyk, K. Błoch, M. Osyra, A. Łukiewska, J. Magn. Magn. Mater. 341, 100\&\#8211; 107 (2013).

[9] I. Betancourt, R. Landa, J. Alloys Comp. 481, 87 (2009).

[10] B.K. Shen, Z.H. Wang, Z.Y. Zhong, J. Chin. Electron Microsc. Soc. 25, 200 (2006).

[11] J. Yu, C. Chang, D. Karns, G. Ju, Y. Kubota, W. Eppler, C. Brucker, D. Weller, J. Appl. Phys. 91, 8357 (2002).

[12] Y. Yang, Y. Wang, Y. Li, X. Bi, Chin. J. Aeronaut. 24, 823 (2011)

[13] H. Kronmüller, J. Appl. Phys. 52, 1859 (1981).

[14] H. Kronmüller, M. Fahnle, Micromagnetism and the microstructure of ferromagnetic solis, Cambridge University Press, Cambridge 2003.

[15] H. Kronmüller, M. Fahnle, H. Grimm, R. Grimm, B. Groger, J. Magn. Magn. Mater. 13, 53 (1979).

[16] H. Kronmüller, IEEE Trans. Magn. 15, \&\#8211; 1225 (1979)

[17] H. Kronmüller, Handbook of Magnetism and Advanced Magnetic Materials, Vol. 2, 2007.

[18] M. Vázquez, W. Fernengel, H. Kronmüller, Physica Status Solidi 115, 547\&\#8211; 553 (1989).

[19] M. Hischer, R. Reisser, R. Würschum, H.E. Schaefer, H. Kronmüller, J. Magn. Magn. Mater. 146, 117 (1995).

[20] N. Lenge, H. Kronmüller, Phys. Status Solidi A 95, 621\&\#8211; 633 (1986). 